ORIGINAL ARTICLE

\title{
Frequency of Placenta Previa in Women with Previous Caesarean Section
}

\author{
ANAHEETA ISRAR ${ }^{1}$, ANUM MALIK², SADIA ANWAR ${ }^{3}$, ZAHRA WASIM ${ }^{4}$, ZUBAIDA KHANUM WAZIR $^{5}$, IRUM BATOOL \\ HASHMI ${ }^{6}$ \\ ${ }^{1}$ Senior Registrar Obs \& Gynae department, Abbottabad Medical Complex, Abbottabad \\ ${ }^{2}$ Exp-PGS Obs \& Gynae department Lady Reading Hospital, Peshawar \\ ${ }^{3}$ Assistant Professor Obs \& Gynae department, Gomal Medical College/ Mufti Mehmood Teaching Hospital, D. I. Khan \\ ${ }^{4}$ Classified Gynaecologist, Combined Military Hospital, Risalpur \\ ${ }^{5}$ Associate Professor Obs \& Gynae department Bannu Medical College, Bannu \\ ${ }^{6}$ Assistant Professor Obs \& Gynae department Gomal Medical College, D. I. Khan \\ Corresponding Author: Dr. Sadia Anwar, Email: sasajjaddr@gmail.com, Cell No: +92 3315894339
}

\begin{abstract}
Objectives: To determine the frequency of placenta previa in women with previous caesarean section presenting at Obstetrics and Gynecology department.

Study Design: Descriptive (cross-sectional) study

Setting and Duration: The study was carried out in the Department of Obstetrics and Gynecology of Abbottabad Medical Complex, Abbottabad and Mufti Mehmood Teaching Hospital, D. I. Khan during from December 2020 to May 2021.

Methodology: The study population included those who have had at least one or more caesarean section, whether emergency or elective and irrespective of the cause of previous caesarean section with age group of 20 to 45 years of age. Patients fulfilling the inclusion and exclusion criteria were enrolled in the study after taking the informed consent. The aims and objectives of the study were explained to the patients being enrolled and their relatives and assured about confidentiality of information. Women included in the study underwent complete history, physical and gynecological examination.

Results: A Total of 147 patients were included in the study sample with placenta previa. Mean age of the patients was $28.69 \pm 6.086$, ranging from 20 to 45 years. Mean value of the parity was $3.18 \pm 1.141$ ranging from 2 to 7 in the descriptive analysis, and the mean of gestational age (weeks) was 39.029 \pm 1.5618 ranging from 36.4 to 41.0 weeks. Out of 147 patients, Placenta previa diagnosed by ultrasound was found in 26(17.7\%) patients.

Conclusion: The study concludes that the frequency of PP in this setting is in keeping with globally cited frequencies. Other findings such as causes of PP and maternal morbidity data also agree with most national and international studies on this topic.
\end{abstract}

Key Words: Placenta previa, Previous Caesarean Section

\section{INTRODUCTION}

Placenta previa (P.P) is an uncommon pregnancy problem where a placenta covers the internal cervical bone in specific or fully to hinder normal vaginal birth. $0.3 \%-0.8 \%$ of all pregnancies worldwide are considered to be complicated ${ }^{1,2}$.

Placenta Previa can have major negative effects, including an increased risk of maternal or neonatal death for both mothers and babies. ${ }^{3}$ It is also one of the primary causes of prepartum bleeding in the second and third quarters. It can cause foetal and mother severe morbidity and death. There is obvious literature support suggesting that placenta preliminaries are more likely not only to occur in patients with a past history of caesarean section, but also in the past with more caesarean section. ${ }^{4}$

Further maternal ages, multiparity, previous Caesarean sections, miscarriages, uterine curretage, cocaine usage, smoking and past history of placenta previous have all been connected to placenta precursor risk factors. The most common recognised aetiological aetiology in singletone pregnancies is prior uterine injury due to recurrent pregnancies or operations. ${ }^{5}$

In the previous one caesarean section, placenta praevia is $16.36 \%$, increasing to $55.56 \%$ with three C sections and $66.67 \%$ with prior four C sections. The screening at an appropriate gestational stage, which is commonly in the second and third trimesters, helps to diagnose placenta preliminary diseases, which can better predict and take early measurements to deal with the problem. ${ }^{6}$

While many research have been done in advance on placenta, investigations in the C-section specifically on placenta are sparse both in the local and in Pakistan. The purpose of our study is to explore for the present frequency of placenta preliminary disease in women with preceding C-section birth, to further improve diagnosis and treatment methods, hence reducing related morbidity and death. Maternal and foetal deaths can be reduced through identification and education for the next pregnancy of highrisk individuals. Even if the results of local and international research may differ, my investigation would offer the recent scale of the problem in the target group, with the same or different results for either population.

\section{METHODOLOGY}

This cross sectional study was conducted at Department of Obstetrics and Gynecology of Abbottabad Medical Complex, Abbottabad and Mufti Mehmood Teaching Hospital, D.I.Khan during from December 2020 to May 2021. After taking approval from the hospitals ethical committee. Participants in the study comprised 147 women who had a previous caesarean scar after 32 weeks of 
pregnancy, whether they had been booked for the procedure or not, with or without vaginal bleeding, and who had visited the OPD or had been admitted for birth. All patients were given a brief explanation of the study's purpose before giving their informed written consent to participate. All of the patients' demographic information, including their name, age, parity, and previous $\mathrm{C}$-section history, was collected before they were assessed in a supine laying posture with an empty urinary bladder. Women having a history of dilatation and curettage ( $D$ \& C), a history of cervical cone biopsy, a history of myomectomy or any other pelvic surgery, and women who were pregnant with multiple children were excluded from the study.

In this study, the placenta was observed in real time on grey scale imaging, and the criteria for defining placenta previa were as follows: abnormally placed placenta in lower uterine segment, partially or completely covering the internal os, either within $5 \mathrm{~cm}$ of the margin from os or completely covering the internal os Transabdominal ultrasonography was used to confirm the presence of a placenta previa. All of the information listed above was entered into a pre-designed proforma. In order to account for confounders and bias, the exclusion criteria were closely followed throughout the study.

Data was analyzed in SPSS version 16.00. Descriptive statistics were calculated for all variables i.e. mean $\pm S D$ were calculated for quantitative variables like age, gestational age and parity. Frequencies and percentages were calculated for categorical variables like placenta previa. Placenta previa was stratified among age, gestational age and parity. Post stratification chi-square test was applied keeping $p$-value $\leq 0.05$ as significant. All results were presented in the form of tables and graphs.

\section{RESULTS}

Out of 147 patients, $112(76.2 \%)$ were ages between 20 to 32 years and $35(23.8 \%)$ patients had ages 33 to 45 years. $104(70.7 \%)$ patients had parity $\leq 3$ while $43(29.3 \%)$ had parity $>3.27(18.4 \%)$ patients had gestational age $\leq 38$ weeks and $120(81.6 \%)$ patients had gestational age $>38$ to 41 weeks. (Table 1)

Table No 1: Baseline details of all the patients

\begin{tabular}{|l|l|l|}
\hline Variables & Frequency No. & $\%$ \%age \\
\hline Age & 112 & 76.2 \\
\hline 20 to 32 yrs & 35 & 23.8 \\
\hline 33 to 45 yrs & 104 & 70.7 \\
\hline Parity & 43 & 29.3 \\
\hline$\leq 3$ & 27 & 18.4 \\
\hline$>3$ & 120 & 81.6 \\
\hline gestational Age (Weeks)
\end{tabular}

Out of 147 patients, Placenta previa diagnosed by ultrasound was found in $26(17.7 \%)$ patients as shown in Figure 1.

Frequency distribution of age in group by placenta previa diagnosed by ultrasound found in group 20 to 32 years was $8(7.1 \%)$, 33 to 45 years was $18(51.4 \%)$, from diagnosed placenta previa i.e. 26 out of 147 patients. This finding is found statistically significant at $p=0.000$. (Table 2)

Frequency distribution of parity in group by placenta previa diagnosed by ultrasound found in group below 3 pregnancies was $8(7.7 \%)$, more than 3 pregnancies was $18(41.9 \%)$, from diagnosed placenta previa i.e. 26 out of 147 patients. This finding is found statistically significant at $\mathrm{p}=0.000$. (Table 3)

\section{Figure No 1: Frequency of Placenta Previa}

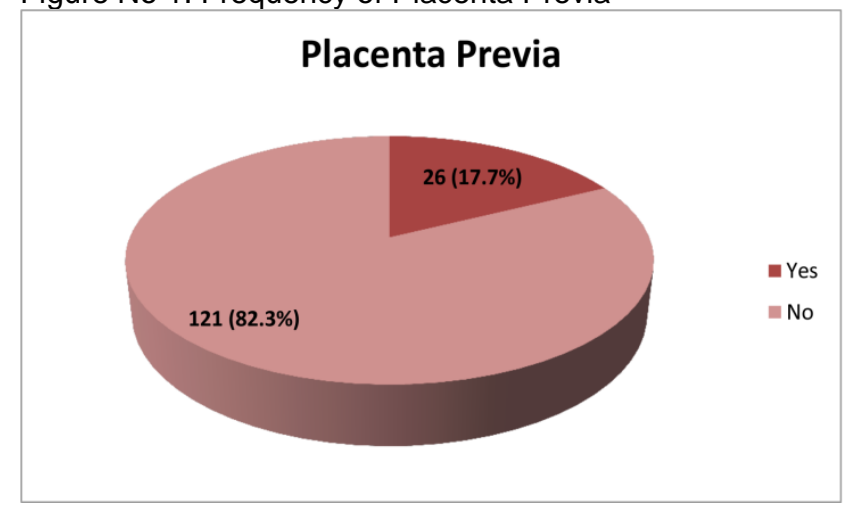

Table 2: Frequency distribution of age in group by placenta previa

\begin{tabular}{|c|c|c|c|c|}
\hline \multirow[t]{2}{*}{ age group } & \multicolumn{2}{|c|}{ Placenta Previa } & \multirow[t]{2}{*}{ Total } & \multirow{2}{*}{$\begin{array}{l}P \text { - } \\
\text { value }\end{array}$} \\
\hline & Yes & No & & \\
\hline \multirow{2}{*}{$\begin{array}{l}20 \text { to } 32 \\
\text { years }\end{array}$} & 8 & 104 & 112 & \multirow{6}{*}{0.000} \\
\hline & $7.1 \%$ & $92.9 \%$ & $100.0 \%$ & \\
\hline \multirow{2}{*}{$\begin{array}{l}33 \text { to } 45 \\
\text { years }\end{array}$} & 18 & 17 & 35 & \\
\hline & $51.4 \%$ & $48.6 \%$ & $100.0 \%$ & \\
\hline \multirow[t]{2}{*}{ Total } & 26 & 121 & 147 & \\
\hline & $17.7 \%$ & $82.3 \%$ & $100.0 \%$ & \\
\hline
\end{tabular}

Table 3: Frequency distribution of parity in group by placenta previa

\begin{tabular}{|l|l|l|l|l|l|}
\hline \multicolumn{2}{|l|}{ parity group } & \multicolumn{2}{|l|}{ Placenta Previa } & Total & $\begin{array}{l}\text { P- } \\
\text { value }\end{array}$ \\
\cline { 3 - 5 } \multicolumn{2}{|c|}{} & Yes & No & & \\
\hline \multirow{2}{*}{$\begin{array}{l}\text { Below 3 } \\
\text { pregnancies }\end{array}$} & 8 & $9.7 \%$ & $92.3 \%$ & 104 & \\
\cline { 2 - 5 } & $\begin{array}{l}\text { More than 3 } \\
\text { pregnancies }\end{array}$ & 18 & 25 & 43 & \multirow{2}{*}{0.000} \\
\cline { 2 - 5 } & $41.9 \%$ & $58.1 \%$ & $100.0 \%$ & \\
\hline
\end{tabular}

Frequency distribution of gestational age in group by placenta previa diagnosed by ultrasound found in gestational age group below 38 weeks was 4(14.8\%), above 38.1 weeks was $22(18.3 \%)$, from diagnosed placenta previa i.e. 26 out of 147 patients. This finding is found statistically insignificant at $p=0.665$. (table 4 )

Table 4: Frequency distribution of gestational age in group by placenta previa

\begin{tabular}{|l|l|l|l|l|l|}
\hline \multicolumn{2}{|l|}{$\begin{array}{l}\text { Gestational age } \\
\text { group }\end{array}$} & \multicolumn{2}{|l|}{ Placenta Previa } & Total & \multirow{2}{*}{$\begin{array}{l}\text { P- } \\
\text { value }\end{array}$} \\
\cline { 3 - 5 } & Yes & No & & \\
\cline { 1 - 5 } & $\begin{array}{l}\text { Below 38 } \\
\text { weeks }\end{array}$ & 4 & 23 & 27 & \\
\cline { 2 - 5 } & $14.8 \%$ & $85.2 \%$ & $100.0 \%$ & \multirow{2}{*}{0.665} \\
\cline { 2 - 5 } & $\begin{array}{l}\text { Above 38.1 } \\
\text { weeks }\end{array}$ & 22 & 98 & 120 & \\
\cline { 2 - 5 } & $18.3 \%$ & $81.7 \%$ & $100.0 \%$ & \\
\hline
\end{tabular}

\section{DISCUSSION}

Placenta Previa is a common obstetrical problem associated with maternal \& fetal morbidity \& mortality. The study showed that major risk factors associated with PP 
were: multiparity, previous history of abortions and previous cesarean sections.

In this study a total of 147 patients were included in the study sample with placenta previa. Mean age of the patients was $28.69 \pm 6.086$, ranging from 20 to 45 years. Mean value of the parity was $3.18 \pm 1.141$ ranging from 2 to 7 in the descriptive analysis, and the mean of gestational age (weeks) was $39.029 \pm 1.5618$ ranging from 36.4 to 41.0 weeks.

In our study placenta previa diagnosed by ultrasound was found in $26(17.7 \%)$ patients. The results were comparable with the study conducted by Uzma $S$ et al, ${ }^{6}$ showing the result of PP low lying placenta. ${ }^{6}$ The results of another study conducted in Saudi Arabia and Sudan were also similar to our study regarding age, gestational age and placenta previa. $^{7}$

In this study the frequency of age group was 20 to 32 years $112(76.2 \%)$ and 33 to 45 years was $35(23.8 \%)$. Many of previsous studies reported that majority $65 \%$ to $75 \%$ patients were ages between 20 to 35 years [8-9].

This study shows the frequency of parity in group was less than 3 was $104(70.7 \%)$ and more than 3 was 43 $(29.3 \%)$ and frequency of gestational age in groups was 'less than 38 weeks' was 27 (18.4\%), '38 to 41 weeks' 120 (81.6\%).

This study shows the frequency distribution of age in group by placenta previa diagnosed by ultrasound found in group 20 to 32 years was $8(7.1 \%), 33$ to 45 years was $18(51.4 \%)$, from diagnosed placenta previa i.e. 26 out of 147 patients. This finding is found statistically significant at $p=0.000$. These results were comparable to many of previous studies $[6,10]$.

Our study shows the frequency distribution of parity in group by placenta previa diagnosed by ultrasound found in group below 3 pregnancies was $8(7.7 \%)$, more than 3 pregnancies was $18(41.9 \%)$, from diagnosed placenta previa i.e. 26 out of 147 patients. Uzma $S$ et al [6] revealed that with increase in parity the risk of placenta praevia increased significantly. In patients who had parity of one the frequency of placenta praevia was (17\%) and in patients having parity of 3 or 4 the frequency of Placenta Praevia became $(36.36 \%)$ and in patient having parity more than 4 the frequency of Placenta Praevia was noted to be (71.42\%).

The frequency distribution of gestational age in group by placenta previa diagnosed by ultrasound found in gestational age group below 38 weeks was $4(14.8 \%)$, above 38.1 weeks was $22(18.3 \%)$, from diagnosed placenta previa i.e. 26 out of 147 patients. This finding is found statistically insignificant at $p=0.665$.

Demographic profiles of patients with APH also provided meaningful data. Subjects had a lower age profile as compared to the international figures [11-13].

The mean age of the patients was $29.70 \pm 6.216$, ranging from 19 to 50 years. The Mean value of the gravidity was $4.19 \pm 2.94$ ranging from 0 to 14 in the descriptive analysis, the mean parity of patients was 2.88. \pm 2.309 ranging from 0 to 13 and the mean of gestational period (weeks) was $34.784 \pm 3.807$ while other studies mention most cases being over 35 years [8, 14].

Previous caesarean delivery has got 5.8 times more risk of developing abnormal placentation in subsequent pregnancies than previous vaginally delivered. This finding is statistically significant. (OR $5.8, \mathrm{Cl} 95 \%, \mathrm{p}<0.001$ ) The other risk factors include advancing maternal age and multiparty. Our findings are consistent with many reports including Wu S et al and Creanga AA et al [15-16].

\section{CONCLUSION}

The study concludes that the frequency of PP in this setting is in keeping with globally cited frequencies. Other findings such as causes of PP and maternal morbidity data also agree with most national and international studies on this topic. Placenta previa remains a risk factor for maternal complications after previous caesarean section, parity, previous placenta previa and assisted conception but the common a risk factor was previous caesarean sectionagree with the findings estimated in previous studies.

\section{REFERENCES}

1. Nankali A, Keshavarzi F, Shajari A, Daeichin S. Frequency of placenta previa and maternal morbidity associated with previous cesarean delivery. Open J Obstet Gynecol. 2014;4:903-8.

2. Wehrum MJ, Buhimschi IA, Salafia C, Thung S, Bahtiyar MO, Werner EF, et al. Accreta complicating complete placenta previa is characterized by reduced systemic levels of vascular endothelial growth factor and by epithelial-to-mesenchymal transition of the invasive trophoblast. Am J Obstetrics Gynecol. $2011 ; 204:(411): e 1-11$

3. Urganci IG, Cromwell DA, Edozien LC, Gordon CS, Smith GCS, Onwere $\mathrm{C}$, et al. Risk of placenta previa in second birth after first birth caesarean section: a population-based study and metaanalysis. BMC Pregnancy Childbirth. 2011;11:95.

4. Goel A. Incidence of placenta previa in previous caesarean section. Inter J Med Sci Res Prac. 2014;1(2):36-9.

5. Bashir A, Jadoon HN, Abbasi AN. Frequency of placenta previa in women with history of previous caesarean and normal vaginal deliveries. J Ayub Med Coll Abbottabad. 2012;24(3-4):151-3.

6. Uzma S, Kiani BF, Khan FS. Frequency of Placenta Praevia with Previous Caesarean Section. Ann Pak Inst Med Sci. 2015;11(4):202-5.

7. 128. Malik S, Naz F. Grandmultiparity- A Continuing Obstetric Risk in Pakistan. J Surg Pakistan 2001; 6: 29-31.

8. Klar M, Michels KB. Cesarean section and placental disorders in subsequent pregnancies--a meta-analysis. J Perinat Med 2014; 42:571.

9. Alouini S, Megier P, Fauconnier A, et al. Diagnosis and management of placenta previa and low placental implantation. J Matern Fetal Neonatal Med 2020; 33:3221.

10. Fan D, Wu S, Liu L, et al. Prevalence of antepartum hemorrhage in women with placenta previa: a systematic review and metaanalysis. Sci Rep 2017; 7:40320.

11. Ruiter L, Eschbach SJ, Burgers M, et al. Predictors for Emergency Cesarean Delivery in Women with Placenta Previa. Am J Perinatol 2016; 33:1407.

12. Jing L, Wei G, Mengfan S, Yanyan $H$. Effect of site of placentation on pregnancy outcomes in patients with placenta previa. PLoS One 2018; 13:e0200252.

13. Baba $\mathrm{Y}$, Matsubara S, Ohkuchi A, et al. Anterior placentation as a risk factor for massive hemorrhage during cesarean section in patients with placenta previa. J Obstet Gynaecol Res 2014; 40:1243.

14. Cheng KK, Lee MM. Rising incidence of morbidly adherent placenta and its association with previous caesarean section: a 15 -year analysis in a tertiary hospital in Hong Kong. Hong Kong Med J 2015;21 (6):511-517.

15. Wu S, Kocherginsky M, Hibbard JU. Abnormal placentation: twenty-year analysis. Am J Obstet Gynecol 2005;192 (5):14581461.

16. Creanga AA, Bateman BT, Butwick AJ, et al. Morbidity associated with cesarean delivery in the United States: is placenta accrete an increasingly important contributor? Am J Obstet Gynecol 2015;213 (3):384.e1- 11. 